une revue Gallia

Centre-Val de Loire | 1998

\title{
Beaugency - 17 rue du Chat-qui-dort
}

$n^{\circ} 064562$

Emmanuelle du Bouëtiez de Kerorguen

\section{(2) OpenEdition}

1 Journals

Édition électronique

URL : https://journals.openedition.org/adlfi/14271

ISSN : 2114-0502

Éditeur

Ministère de la Culture

Référence électronique

Emmanuelle du Bouëtiez de Kerorguen, « Beaugency - 17 rue du Chat-qui-dort » [notice

archéologique], ADLFI. Archéologie de la France - Informations [En ligne], Centre-Val de Loire, mis en ligne le 20 mars 2015, consulté le 09 juin 2021. URL : http://journals.openedition.org/adlfi/14271

Ce document a été généré automatiquement le 9 juin 2021.

(C) ministère de la Culture et de la Communication, CNRS 


\title{
Beaugency - 17 rue du Chat-qui- dort
}

$n^{\circ} 064562$

\author{
Emmanuelle du Bouëtiez de Kerorguen
}

Lien Atlas (MCC) :

http://atlas.patrimoines.culture.fr/atlas/trunk/index.php?

ap_theme=DOM_2.01.02\&ap_bbox=1.607;47.747;1.669;47.808

1 Un projet immobilier a motivé une évaluation archéologique menée du $1^{\mathrm{er}}$ au 12 décembre 1998. Ce site de $1008 \mathrm{~m}^{2}$ est implanté de part et d'autre de la troisième enceinte de la ville et conserve encore en élévation une portion de cette dernière.

De manière générale, le site est fortement perturbé par des constructions d'époque contemporaine. Malgré cela, il est possible de tirer quelques enseignements sur l'occupation des lieux aux époques antérieures.

3 Le fossé a été remblayé tardivement concomitamment à l'installation de caves s'appuyant contre l'escarpe et la contrescarpe. L'étude du contenu des remblais tout autant que celle du cadastre permettent de proposer comme date la première moitié du $\mathrm{XIX}^{\mathrm{e}} \mathrm{s}$. La largeur du fossé peut être estimée à une douzaine de mètres. Le fond n'a pu être atteint avec certitude. Une lice d'environ 3,40 $\mathrm{m}$ de large subsistait entre le fossé et le mur d'enceinte. Celui-ci a été détruit en partie au siècle dernier. Il n'est plus conservé que sur $7 \mathrm{~m}$ de long. Ses fondations n'excèdent pas $1 \mathrm{~m}$ de profondeur, elles reposent sur le sol naturel fait d'un sédiment argilo-sableux. Aucun mobilier archéologique n'apporte d'indice de datation permettant de confirmer ou d'infirmer la date supposée de construction de l'ouvrage (premier tiers du $\mathrm{XI}^{\mathrm{e}} \mathrm{s}$.).

4 La partie intra-muros ne recèle aucune trace de bâti antérieur au XIX ${ }^{\mathrm{e}} \mathrm{s}$. Seuls des remblais et deux fosses datables de la fin du Moyen Âge attestent la présence humaine à proximité. L'indigence du mobilier archéologique ainsi que la nature des sédiments permettent de penser que cet espace situé entre l'enceinte et la rue, mesurant une vingtaine de mètres de large, était constitué de champs ou de terrains vagues formant 
une zone de circulation. Il est vraisemblable que la rue du Chat-qui-Dort, dont le tracé parallèle à l'enceinte est sûrement très ancien, marquait la limite des habitations. 